\title{
THE EFFICACY OF HIGH-DOSE SIMVASTATIN IN ACUTE PERIOD OF ISCHEMIC STROKE
}

\author{
V.V.Yakusevich1* , A.Yu.Malygin², S.V.Lychenko1, A.S.Petrochenko1, A.V.Kabanov \\ 1 Yaroslavl State Medical Academy. Revolutsionnaya ul. 5, Yaroslavl, 150000 Russia \\ 2 Yaroslavl Municipal Clinical Hospital №8. Tereshkovoy ul. 22, Yaroslavl, 150000 Russia
}

The efficacy of high-dose simvastatin in acute period of ischemic stroke

V.V.Yakusevich1* A.Yu.Malygin2 2 S.V.Lychenko ${ }^{1}$ A.S. Petrochenko ${ }^{1}$ A.V.Kabanov ${ }^{1}$

1 Yaroslavl State Medical Academy. Revolutsionnaya ul. 5 , Yaroslavl, 150000 Russia

2Yaroslavl Municipal Clinical Hospital №8. Tereshkovoy ul. 22, Yaroslavl, 150000 Russia

Aim. To estimate in a 12-month study mortality and frequency of recurrent cardiovascular events, dynamics of neurological deficit and endothelial dysfunction in patients with the first-time ischemic stroke treated with simvastatin $40 \mathrm{mg} /$ day in acute period of the disease.

Materials and methods. The efficacy of high-dose simvastatin ( $40 \mathrm{mg} /$ day) therapy initiated in acute stage of ischemic stroke was evaluated in 12 -month comparative randomized study. Patients of the first group $(n=97)$ received standard stroke therapy, and patients of the second group $(n=86)$ also received standard treatment and simvastatin additionally. Combined endpoint (cardiovascular death + recurrent cardiovascular events + necessity of readmission), dynamics of neurological status and endothelial function were considered.

Results. Primary combined endpoint was achieved in 66 cases in the first group (68.04\%) and in $47(54.65 \%)$ in the second one ( $p=0.043)$. Neurological status evaluated by National Institutes of Health Stroke Scale (NIHSS), Mini-Mental State Examination (MMSE) scale, and Scandinavian scales had a faster positive dynamics in patients receiving simvastatin. The same patients revealed more intense and quick decrease in desquamated plasma endotheliocytes.

Conclusion. Simvastatin $40 \mathrm{mg} /$ day prescribed along with neuroprotective and antihypertensive treatment in acute stage of ischemic stroke leads to lowering of recurrent cardiovascular events number positive dynamics of neurological status, regression of endothelial dysfunction reflected by significant decrease in number of circulating desquamated endotheliocytes.

Key words: ischemic stroke, simvastatin, high dose, endothelial dysfunction, cardiovascular events.

Rational Pharmacother. Card. 2012;8(1):4-16

Эффективность высокой дозы симвастатина при назначении препарата в остром периоде ишемического инсульта

В.В. Якусевич ${ }^{*}$, А.Ю. Малыгин², С.В. Лыченко , А.С. Петроченко1, А.В. Кабанов ${ }^{1}$

1Ярославская государственная медицинская академия. 150000 , Ярославль, ул. Революционная, 5

2Городская клиническая больница № 8 г. Ярославль. 150000, Ярославль, ул. Терешковой, 22

Цель. Оценить в 12-месячном наблюдении смертность, частоту повторных кардиоваскулярных событий, динамику неврологического дефицита и эндотелиальной дисфункции у пациентов с впервые возникшим ишемическим инсультом при назначении симвастатина 40 мг в остром периоде болезни.

Материал и методы. В 12-месячном сравнительном рандомизированном исследовании оценена эффективность терапии высокой дозой симвастатина (40 мг), назначаемого пациентам в остром периоде ишемического инсульта. Пациенты первой группы ( $\mathrm{n=97)}$ получали стандартную терапию инсульта, а пациенты второй группы ( $\mathrm{n}=86)$ - симвастатин в дополнение к стандартной терапии. Учитывали комбинированную конечную точку (сердечно-сосудистая смерть + повторные кардиоваскулярные катастрофы + необходимость повторной госпитализации), а также динамику неврологического статуса и эндотелиальной функции.

Результаты. Первичная комбинированная конечная точка была достигнута в 66 случаях в первой группе (68,04\%), и в 47 (54,65\%) во второй при р=0,043. Оценка неврологического статуca пo NIHSS (National Institutes of Health Stroke Scale), MMSE (Mini-Mental State Examination) и скандинавской шкалам продемонстрировала достоверно более быструю положительную его динамику у пациентов, принимавших симвастатин. В этой же группе отмечено более значительное и быстрое уменьшение в плазме клеток десквамированного эндотелия.

Заключение. Назначение 40 мг симвастатина больным в острой фазе ишемического инсульта наряду с сопутствующей нейропротекторной и антигипертензивной терапией способствует уменьшению количества повторных кардиоваскулярных катастроф, положительной динамике неврологического статуса и регрессу проявлений эндотелиальной дисфункции в виде значительного уменьшения количества циркулирующих в крови клеток десквамированного эндотелия.

Ключевые слова: ишемический инсульт, симвастатин, высокая доза, эндотелиальная дисфункция, сердечно-сосудистые события.

Ключевые слова: ише
РФК 2012;8(1):4-16

*Corresponding author (автор, ответственный за переписку): yakusevich@yandex.ru

Acute cerebrovascular accidents are the mostly important medical and social problems due to their large share in population's morbidity and mortality, and significant rates of temporary and permanent disability. Stroke is the reason for about one third of all cardiovascular deaths [1,2], at that disability occurs in up to $60 \%$ of survived patients $[3,4]$. If no global measures are taken to deal with this epidemy, fatal stroke rate will increase up to 6.7 million in 2015 and up to 7.8 million in 2030 [5]. More than 400 thousands of strokes are registered in Russia yearly with incidence rate of ischemic strokes (IS) about 70-85\% [6, 7].

Cerebrovascular risk increases by more than 10 -fold in patients who underwent stroke or transitory ischemic
Острые нарушения мозгового кровообращения (ОНМК) являются важнейшей медико-социальной проблемой, что обусловлено их высокой долей в структуре заболеваемости и смертности населения, а также значительными показателями временных трудовых потерь и первичной инвалидности. На долю инсульта приходится почти треть всех случаев сердечно-сосудистой смерти [1, 2], а у выживших больных инвалидизация составляет более $60 \%[3,4]$. Если не будет предпринято никаких глобальных мер по борьбе с этой эпидемией, в 2015 г. прогнозируется рост количества случаев смерти от инсульта до 6,7 млн, а в 2030 г. - до 7,8 млн [5]. В России регистрируется более 400 тыс инсультов в год, среди которых более часто (70-85\%) встречаются ишемические инсульты $[6,7]$.

\section{Authors' information:}

Vladimir V. Yakusevich - PhD, MD, Professor, Chair of clinical

pharmacology, Yaroslavl State Medical Academy

Aleksandr Yu. Malygin - PhD, MD, Head of resuscitation unit Yaroslavl Municipal Clinical Hospital №8

Sergei V. Lychenko-MD, PhD. student, Chair of clinical pharmacology, Yaroslavl State Medical Academy

Aleksandr S. Petrochenko - PhD, MD, assistant of the same Chair Andrei V. Kabanov - PhD, MD, assistant of the same Chair
Сведения об авторах:

Якусевич Владимир Валентинович - д.м.н., профессор кафедры клинической фармакологии ЯГМА

Малыгин Александр Юрьевич - К.м.н., зав. отделением реанимации ГКБ №8 Ярославля

Лыченко Сергей Валерьевич - аспирант кафедры клинической фармакологии ЯГМА

Петроченко Александр Сергеевич - К.м.Н., ассистент той же кафедры Кабанов Андрей Викторович - К.м.Н., ассистент той же кафедры 
attack (TIA). Second IS occurs in nearly $30 \%$ of patients during the five years after the first stroke with the highest risk of the recurrence in the first year. Probability of lethal outcome and disability is higher at recurrent stroke than at the first one. That is why secondary prevention should be started as soon as possible after the first stroke or TIA. It is based on risk factors correction and includes both medicamental and non-medicated methods. The most significant modified IS risk factors are the following: smoking, alcohol abuse, arterial hypertension $(\mathrm{HT})$, carotid atherosclerosis, dyslipidemia and diabetes mellitus [6-9].

The leading pathogenetic mechanism of IS is atherothrombosis. At that instability of an atherosclerotic plaque with its disruption, resulting in cascade of hemostatic processes is regarded as more significant than its total extent. In accordance to contemporary conception of atherosclerosis and atherothrombosis clinical manifestation of majority of cardiovascular events is directly associated with the moment of atherosclerotic plaque rupture [10]. Impairment of vessel wall functional properties participates in brain vascular disease development as well as structure changes of cerebral vasculature. Vascular endothelium which is both the target organ for HT and atherosclerosis and an effector in pathogenesis of these conditions is in the focus of attention in present days [11]. At that vessels reveal a variety of morphologic changes of adaptive, destructive and reparative character with different intensity, extent and duration [5].

Adequate homeostasis is maintained due to the function of undamaged endothelium which keeps balance in the following contrary processes: vessel tonus (vasodilatation/vasoconstriction); vessel structure (synthesis/inhibition of proliferative factors); coagulation (synthesis and inhibition of fibrinolysis and platelets aggregation factors); local inflammation (production of pro- and anti-inflammatory factors) [1217]. At that each of these four endothelium functions, determining thrombogenicity of vascular wall, is directly or indirectly associated with atherosclerosis onset and progression [18-20]. In accordance to contemporary data the reason for endothelium dysfunction is its chronic impairment which results in platelets adhesion to subendothelium layer and their aggregation, release of growth factors facilitating migration of smooth muscle cells from media to intima, which promotes formation of fibrotic plaque, thrombosis, neoangiogenesis, vessel remodeling, intravascular platelets and leucocytes activation and some other processes. All the above mentioned mechanisms realize cerebrovascular diseases onset and progression. Patients with vascular damages also reveal increased inflammatory markers (C-reactive
У лиц, перенесших инсульт или транзиторную ишемическую атаку (ТИА), вероятность повторного цереброваскулярного эпизода увеличивается более чем в 10 раз. Повторный ишемический инсульт возникает примерно у $30 \%$ больных в период пяти лет с момента первого инсульта, его риск особенно велик в первый год после заболевания. Вероятность смертельного исхода и инвалидности при повторном ишемическом инсульте выше, чем при впервые возникшем, поэтому вторичная профилактика должна начинаться как можно раньше после развития первого инсульта или ТИА. Она основывается на коррекции факторов его риска и включает как лекарственные, так и нелекарственные средства профилактики. К наиболее значимым корригируемым факторам риска ишемического инсульта относят курение, злоупотребление алкоголем, артериальную гипертензию (АГ), атеросклероз сонных артерий, дислипидемию, заболевания сердца и сахарный диабет [6-9].

Атеротромбоз является ведущим патогенетическим механизмом развития ишемического инсульта. При этом нестабильность атеросклеротической бляшки с последующим ее разрывом и запуском каскада процессов гемостаза признается более значимой, чем ее абсолютный объем. Согласно современной концепции атеросклероза и атеротромбоза, клиническая манифестация большинства сердечно-сосудистых катастроф непосредственно связана с моментом нарушения целостности атеросклеротической бляшки [10]. Большое значение в развитии сосудистых заболеваний головного мозга имеют не только структурные изменения церебрального сосудистого русла, но и нарушения функциональных свойств сосудистой стенки. В настоящее время основным объектом внимания исследователей стал эндотелий сосудов, который считается как органом-мишенью для АГ и атеросклероза, так и эффектором в патогенезе данных состояний [11]. Морфологические изменения, обнаруживаемые при этом в сосудах, имеют характер адаптивных, деструктивных и репаративных, однако степень их выраженности, давности и распространенности неодинакова на каждом из основных структурно-функциональных уровней [5].

Функционирование неповрежденного эндотелия во многом определяет поддержание адекватного гомеостаза путем регуляции равновесного состояния противоположных процессов - тонуса сосудов (вазодилатация/вазоконстрикция); их структуры (синтез/ингибирование факторов пролиферации); коагуляции (синтез и ингибирование факторов фибринолиза и агрегации тромбоцитов); местного воспаления (выработка про- и противовоспалительных факторов) [12-17]. При этом каждая из четырех вышеперечисленных функций эндотелия, определяющих тромбогенность сосудистой стенки, напрямую или косвенно связана с развитием и прогрессированием атеросклероза [18-20]. Дисфункция эндотелия, согласно наиболее современной гипотезе, развивается вследствие хронического его повреждения, что приводит к адгезии тромбоцитов к суб- 
protein, fibrinogen) and immunoglobulins level [21]. Inflammatory cells stimulate destruction of extracellular matrix followed by thrombosis in the point of a plaque rupture.

Stroke primary and secondary prevention is one of the priorities for the present-day medicine. Medical treatment of IS is discussed in detail in respective clinical guidelines and recommendations [22]. Adequate antihypertensive therapy was proved to decrease risk of stroke significantly. In the last years antiplatelet and anticoagulant therapy has been shown to benefit in patients with heart rhythm disturbance and congestive heart failure. However advisability of lipid-lowering treatment for stroke prevention remained unclear for a long time. Some studies demonstrate positive influence of lipid-lowering drugs (mainly, statins) on outcomes and relapses of cerebrovascular disease [23, 24], while the others show worse results [25]. At that there is no agreement of opinions how early these drugs should be prescribed to IS patients. Early statin administration is absolutely justified in ischemic heart disease, while advantage of statin intake in acute period of stroke is disputable and requests further investigations. Inhibitors of HMG-CoA-reductase (statins) are forceful anti-inflammatory remedy. They reduce leukocytic adhesion to endothelium by decreasing expression of special endothelial and leukocytic adhesive molecules and slow down inflammatory cells migration to a zone of inflammation. In experiment statins demonstrated direct anti-inflammatory effect which is similar with that in the main anti-inflammatory drugs (for example, indometacin). Controlled clinical trial showed simvastatin $40 \mathrm{mg} /$ day significantly decreased C-reactive protein level already by the 14th day of the treatment as compared to a placebo group [26].

Statins are thought to improve brain arteries reactivity due to increase of nitric oxide (NO) secretion by vascular endothelium. Nitric oxide, which is produced at participation of endothelial NO-synthetase, reveals protective activity at ischemia, regulates leucocytes and platelets adhesion and activation, dilates vessels and keeps anti-thrombotic activity of vascular wall. On the other hand, neuronal NO-synthetase (NOS1) facilitates brain ischemic necrosis as it participates in ischemic reperfusive damage. Among statins various effects connected with mevalonate synthesis blockade their regulatory impact on NO-synthetase isoforms may be essential for stroke prevention [27]. Statins seem to influence on endothelial dysfunction both through normalization of blood lipid profile and direct effect on endothelium (regardless of blood lipid profile) [28].

Endothelium desquamation, being one of the markers of its damage, can be estimated by the count of circulating (desquamated) endotheliocytes in pe- эндотелиальному слою и их агрегации, высвобождению факторов роста, способствующих миграции гладкомышечных клеток из медии в интиму с образованием фиброзных бляшек, развитию тромбоза, неоангиогенеза, ремоделирования сосудов, внутрисосудистой активации тромбоцитов и лейкоцитов и т.д. Развитие и прогрессирование цереброваскулярных заболеваний (ЦВЗ) опосредуются всеми перечисленными механизмами, а также отмечаются повышением у больных с сосудистыми поражениями уровня маркеров воспаления (С-реактивный белок, фибриноген) и иммуноглобулинов [21]. Воспалительные клетки могут стимулировать разрушение внеклеточного матрикса с последующим развитием тромбоза в месте разрыва бляшки.

Первичная и вторичная профилактика мозговых инсультов справедливо считается одной из приоритетных задач современной медицины. Подходы к лекарственной терапии ишемического инсульта подробно освещены в соответствующих руководствах и клинических рекомендациях [22]. Убедительно доказано, что адекватная гипотензивная терапия существенно снижает риск инсультов. За последние годы несомненным успехом в этой области стало активное назначение антитромбоцитарных и антикоагулянтных препаратов при нарушениях сердечного ритма и застойной сердечной недостаточности. Однако довольно долгое время оставалась неясной целесообразность гиполипидемической терапии для профилактики мозговых инсультов. В литературе имеются как данные по позитивному влиянию гиполипидемических препаратов (прежде всего статинов) на исходы и рецидивы нарушений мозгового кровообращения $[23,24]$, так и более скромные результаты исследований в этой области [25]. При этом у сторонников терапии статинами нет единого мнения о том, как рано следует назначать эти препараты пациентам с ишемическим инсультом. Если при ишемической болезни сердца раннее назначение статинов считается безусловно оправданным, то польза применения этих препаратов уже в острой стадии мозгового инсульта окончательно не выяснена и требует дополнительных исследований. Ингибиторы ГМГ-КоА-редуктазы (статины) являются мощными противовоспалительными препаратами. Они снижают адгезию лейкоцитов с эндотелием, уменьшая экспрессию специальных эндотелиальных и лейкоцитарных адгезивных молекул, снижают скорость миграции воспалительных клеток в зону воспаления. В эксперименте зарегистрировано прямое противовоспалительное действие этих лекарственных средств, сопоставимое по силе с таковым основных противовоспалительных препаратов (например, индометацина). В контролируемом клиническом исследовании применение симвастатина в дозе 40 мг/сут приводило к выраженному снижению С-реактивного белка по сравнению с группой плацебо уже на 14 день лечения [26].

Наибольшее внимание исследователи уделяют улучшению реактивности мозговых артерий под влиянием статинов, в основе которой, как полагают, находится повыше- 
ripheral blood [29]. So, increase in the number of circulating endotheliocytes $[30,31]$ in patients with IS reflects degree of vessel wall damage [17].

Consequently, blood count of desquamated endotheliocytes being an early predictor of stroke severity can be used in secondary prevention planning.

The 12-month study was aimed at the estimation of mortality and frequency of recurrent cardiovascular events, dynamics of neurological deficit and endothelial dysfunction in patients with the first-time IS who received simvastatin $40 \mathrm{mg} /$ day in acute period of the disease.

\section{Material and methods}

The total of 183 patients ( 80 men, 103 women; aged $65.69 \pm 8.3$ years) with the first acute ischemic cerebrovascular accident in carotid system were enrolled into the study. The diagnosis was verified by computer or magnetic resonance tomography of brain in acute stage of the disease (24-48 hours from the first symptoms onset). The consciousness level of the patients varied from clear to moderate stupor (13-15 points by the Glasgow coma scale). The patients were being enrolled during 2008-2010.

Patients with recurrent stroke, hemorrhagic stroke, consciousness level below 13 points by the Glasgow scale as well as patients with presumably unfavorable concomitant diseases were excluded from the study.

Death of a patient, all the cases of recurrent cardiovascular events and necessity for repeated hospitalization were considered as the primary combined endpoint. Mortality rate, dynamics of neurological status and desquamated endotheliocytes count were the secondary endpoints.

The study protocol and the form of informed consent were approved by the Ethical Committee of Yaroslavl State Medical Academy. All the enrolled patients had signed informed consent.

The patients were randomized into two groups via the method of envelopes. The first group included 97 patients (43 men, 54 women; aged $65.81 \pm 9.3$ years) who received standard treatment of IS. The second group included 86 patients ( 37 men, 49 women, aged $65.55 \pm 7.2$ years) who received simvastatin 40 $\mathrm{mg}$ (Zocor forte, MSD, Switzerland) in addition to the standard therapy. The drug was prescribed once a day in the evening.

The standard therapy included antiplatelet drugs (acetylsalicylic acid), neurotrophic drugs and neuromodulators, correction of HT, atrial fibrillation and chronic heart failure (CHF). The follow-up period was as much as 12 months. All the patients were examined during the first three days (visit of inclusion) and then on 90, $180,360^{\text {th }}$ days of the follow-up. ние секреции оксида азота (NO) сосудистым эндотелием. Оксид азота, образуемый с участием эндотелиальной NOсинтетазы, обладает протективной активностью при ишемии, регулирует адгезию и активацию лейкоцитов и тромбоцитов, вызывает расширение сосудов, поддерживает антитромботическую активность сосудистой стенки. С другой стороны, нейрональная NO-синтетаза (NOS1) содействует развитию ишемических некрозов мозга, поскольку участвует в формировании ишемического реперфузионного повреждения. Среди разнообразных эффектов статинов, связанных с блокадой синтеза мевалоната, их регулирующее воздействие на изоформы NO-синтетазы может иметь значение для предупреждения инсультов [27]. Влияние статинов на эндотелиальную дисфункцию, вероятно, происходит опосредованно через нормализацию липидного спектра крови и с помощью прямого воздействия на эндотелий (вне зависимости от воздействия на липидный спектр крови) [28].

Одним из маркеров повреждения сосудистого эндотелия является степень его десквамации, которую отражает количество циркулирующих (десквамированных) эндотелиоцитов в крови [29]. Увеличение числа циркулирующих эндотелиоцитов $[30,31]$ у пациентов, перенесших ишемический инсульт, рассматривается как показатель степени повреждения сосудистой стенки [17].

Из вышеизложенного вытекает стратегия вторичной профилактики цереброваскулярных нарушений. Она заключается прежде всего в выявлении ранних предикторов прогноза тяжести инсульта, в качестве которых может выступать определение числа десквамированных эндотелиальных клеток.

Цель исследования - оценить в 12-месячном наблюдении смертность, частоту повторных кардиоваскулярных событий, динамику неврологического дефицита и эндотелиальной дисфункции у пациентов с впервые возникшим ишемическим инсультом при назначении симвастатина 40 мг/сут в остром периоде болезни.

\section{Материал и методы}

В исследование включены 183 пациентов (мужчин - 80, женщин - 103; возраст - 65,69 8,3 лет) с впервые возникшим ОНМК по ишемическому типу в каротидной системе, верифицированного с помощью компьютерной или магнитно-резонансной томографии головного мозга в острый период заболевания (в течение 24-48 ч от момента появления первых симптомов). Уровень сознания пациентов на момент включения был от ясного до умеренного оглушения (13-15 баллов по шкале ком Глазго). Набор пациентов проводился в 2008-2010 гг.

В исследование не включались пациенты с повторным OHMК, геморрагическим инсультом, уровнем сознания менее 13 баллов по шкале Глазго, а также больные, имеющие прогностически неблагоприятные сопутствующие заболевания. 
Examination included the following: vital functions control; assessment of standard blood indices, the total cholesterol (TC), cholesterol of low density lipoproteins (LDL) and triglycerides (TG) levels; estimation of neurological status by Mini-Mental State Examination (MMSE) scale, National Institutes of Health Stroke Scale (NIHSS) and Scandinavian scale.

Plasma desquamated endotheliocytes were also counted in all the patients on 1, 7, 21,90, 180 and $360^{\text {th }}$ days of the study.

Data were classified in accordance to examined attributes type. Distribution patterns were estimated by the Shapiro-Wilk test. Accuracy of quantitative data was determined by measurement accuracy of a used procedure or a device. Then the examined groups were compared. Statistical data processing was performed with help of conventional methods of variance analysis. Normal or close to normal distribution of the examined parameters allowed application of parametric criteria for statistical analysis. Variables were compared using Student t-test. Distinctions were considered significant at $p<0.05$. Statistical processing was performed using software package STATISTICA ${ }^{\circledR}$ (Data analysis software system, StatSoft Inc. 2004) version 7.0.

\section{Results}

Due to randomization patients didn't distinguish in basic clinic and demographic parameters (Table 1). Comorbidity (Table 2) and treatment (Table 3) were also similar.
В качестве комбинированной первичной конечной точки учитывались смерть больного, а также все случаи повторных сердечно-сосудистых событий и необходимость в повторной госпитализации. Вторичными конечными точками выступали летальность, динамика неврологического статуса и подсчет клеток десквамированного эндотелия.

Протокол исследования и форма информированного согласия пациента были одобрены Этическим комитетом ЯГМА. Пациенты, включенные в исследование, подписали информированное согласие.

Пациенты были рандомизированы методом конвертов в две группы наблюдения. В группу 1 были включены 97 па-

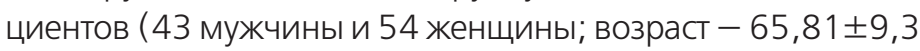
лет), получавших стандартное лечение ишемического инсульта. Группу 2 составили 86 пациентов (37 мужчин и 49

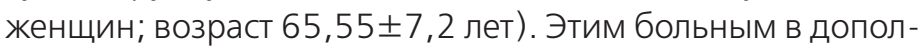
нение к стандартной терапии инсульта было назначено 40 мг симвастатина (Зокор-форте, MSD, Швейцария). Препарат применялся в вечерние часы один раз в сутки.

Стандартная терапия включала антиагреганты (аспирин), нейротрофические препараты и нейромодуляторы, коррекцию АГ, фибрилляции предсердий и хронической сердечной недостаточности (XCH). Период наблюдения составил 12 мес, во время которых всем пациентам проводилось комплексное обследование в первые трое суток (визит включения) и далее на 90, 180 и 360 день исследования.

Помимо контроля жизненно важных функций, стандартных показателей крови, уровней общего холестерина (OX), холестерина липопротеидов низкой плотности (Х-ЛПНП) и триглицеридов (ТГ) производились оценка неврологического статуса по шкалам Mini-Mental State

Table 1. Randomization. Initial clinic and demographic parameters

Таблица 1. Рандомизация. Исходные клинико-демографические показатели

\begin{tabular}{|c|c|c|c|}
\hline Parameter/Показатель & Group 1 / Группа 1 (n=97) & Group 2 / Группа 2 (n=86) & $p$ \\
\hline Age, years / Возраст, лет & $65.8 \pm 9.3$ & $65.5 \pm 7.2$ & 0.9 \\
\hline Men / Мужчины, n (\%) & $43(44.3 \%)$ & $37(43.02 \%)$ & 0.91 \\
\hline Women / Женщины, n (\%) & $54(55.7 \%)$ & $49(56.98 \%)$ & 0.92 \\
\hline Systolic BP, mm Hg / Систолическое АД, мм рт.ст. & $156.4 \pm 15.8$ & $156.4 \pm 15.3$ & 0.9 \\
\hline Diastolic BP, mm Hg / Диастолическое АД, мм рт.ст. & $84.2 \pm 9.8$ & $83.9 \pm 9.7$ & 0.8 \\
\hline HR, bt/min / ЧСС, уд/мин & $85.7 \pm 11.3$ & $85.9 \pm 12.5$ & 0.9 \\
\hline TC, mmol/l / OХ, ммоль/л & $5.22 \pm 1.70$ & $5.47 \pm 1.30$ & 0.2 \\
\hline LDL cholesterol, mmol/l / Х-ЛПНП, ммоль/л & $2.23 \pm 0.90$ & $2.2 \pm 0.60$ & 0.8 \\
\hline TG, mmol/l / ТГ, ммоль/л & $1.03 \pm 0.20$ & $1.16 \pm 0.40$ & 0.4 \\
\hline NIHSS, points / баллы & $9.19 \pm 3.74$ & $8.86 \pm 4.02$ & 0.7 \\
\hline MMSE, points / баллы & $17.24 \pm 3.35$ & $17.41 \pm 3.80$ & 0.4 \\
\hline Scandinavian scale, points / Скандинавская шкала, баллы & $37.17 \pm 2.19$ & $36.92 \pm 2.52$ & 0.2 \\
\hline $\begin{array}{l}\text { Blood count of desquamated endothelium, cells number per } \\
\text { high power field / Клетки десквамированного эндотелия, } \\
\text { количество в поле зрения }\end{array}$ & $17.81 \pm 3.35$ & $17.62 \pm 6.40$ & 0.8 \\
\hline
\end{tabular}


Table 2. Randomization. Comorbidity

Таблица 2. Рандомизация. Сопутствующая патология

\begin{tabular}{|c|c|c|c|}
\hline Disease / Заболевание & Group 1 / Группа 1 (n=97) & Group 2 / Группа 2 (n=86) & p \\
\hline HT / AГ, n (\%) & $74(76.3 \%)$ & $68(73.3 \%)$ & 0.87 \\
\hline Previous MI / ИМ в анамнезе, n(\%) & $8(8.2 \%)$ & $10(8.6 \%)$ & 0.48 \\
\hline $\mathrm{AF} /$ ФП, $\mathrm{n}(\%)$ & $12(12.4 \%)$ & $14(16.3 \%)$ & 0.51 \\
\hline СОРD / ХОБЛ, n (\%) & $6(6.2 \%)$ & $5(5.8 \%)$ & 0.92 \\
\hline DM type 2 / СД 2 типа, n (\%) & $10(9.7 \%)$ & $8(9.3 \%)$ & 0.83 \\
\hline Chronic diseases of GIT / Хронические заболевания ЖKT, n (\%) & $12(12.4 \%)$ & $9(10.5 \%)$ & 0.71 \\
\hline \multicolumn{4}{|c|}{$\begin{array}{l}\text { HТ - arterial hypertension, MI - myocardial infarction, AF - atrial fibrillation, COPD - chronic pulmonary lung disease, DM - diabetes mellitus, GIT - gastro-intestinal tract. } \\
\text { АГ - артериальная гипертония, ИМ - инфаркт миокарда, ФП - фибрилляция предсердий, ХОБЛ - хроническая обструктивная болезнь легких, СД - сахарный диабет, } \\
\text { ЖКТ - желудочно-кишечный тракт }\end{array}$} \\
\hline
\end{tabular}

Table 3. Drugs used in the treatment

Таблица 3. Лекарственные средства, применявшиеся при лечении

\begin{tabular}{|c|c|c|c|}
\hline Drug / Лекарственные средства & Group 1 / Группа 1 (n=97) & Group 2 / Группа 2 (n=86) & p \\
\hline Cerebrolysin / Церебролизин, n (\%) & $16(16.5 \%)$ & $13(15.1 \%)$ & 0.82 \\
\hline Aminophylline / Эуфиллин, n (\%) & $46(47.4 \%)$ & $48(55.8 \%)$ & 0.52 \\
\hline Vinpocetine / Винпоцетин, n (\%) & $65(67.0 \%)$ & $58(67.4 \%)$ & 0.97 \\
\hline Actovegin / Актовегин, n (\%) & $26(26.8 \%)$ & $28(16.5 \%)$ & 0.53 \\
\hline Enalapril / Эналаприл, n (\%) & $82(84.5 \%)$ & $76(88.4 \%)$ & 0.83 \\
\hline Metoprolol / Метопролол, n (\%) & $68(70.1 \%)$ & $62(72.1 \%)$ & 0.90 \\
\hline Amiodarone / Амиодарон, n (\%) & $5(5.2 \%)$ & $3(3.5 \%)$ & 0.59 \\
\hline Digoxin / Дигоксин, n (\%) & $8(8.2 \%)$ & $8(9.3 \%)$ & 0.81 \\
\hline Glycine / Глицин, n (\%) & $97(100.0 \%)$ & $86(100.0 \%)$ & 1 \\
\hline Acetylsalicylic acid / Ацетилсалициловая кислота, n (\%) & $88(90.7 \%)$ & $81(94.2 \%)$ & 0.86 \\
\hline Dipyridamol / Дипиридамол, n (\%) & $1(1.0 \%)$ & $0(0.0 \%)$ & 0.34 \\
\hline Clopidogrel / Клопидогрел, n (\%) & $1(1.0 \%)$ & $1(1.2 \%)$ & 0.93 \\
\hline Heparin / Гепарин, n (\%) & $13(13.4 \%)$ & $8(9.3 \%)$ & 0.43 \\
\hline Gliatilin / Глиатилин, n (\%) & $18(18.6 \%)$ & $13(15.1 \%)$ & 0.60 \\
\hline Simvastatin 40 mg/day / Симвастатин 40 мг, n (\%) & $0(0 \%)$ & $86(100 \%)$ & 0.00 \\
\hline
\end{tabular}

9 of 183 patients enrolled into the study had died by the $90^{\text {th }}$ day of the follow-up ( 6 patients of the first group and 3 - of the second one) and 19 patients ( 11 and 8 people, respectively, $\mathrm{p}>0.05$ ) had died by the middle of the follow-up ( $180^{\text {th }}$ day). By the end of the follow-up number of deceased patients was still higher in the first group, but these distinctions were statistically insignificant ( 16 deceased in the group 1 and 13 - in the group 2, Table 4).

The both groups revealed approximately similar rate of cardiovascular events during the follow-up: the first group - 12.37\% $(n=12)$ and the second one $11.63 \%(n=10), p>0.05$ (Table 5 ).

Besides, 38 patients $(39.2 \%)$ of the first group and 24 (27.9\%) of the second one were hospitalized for various reasons. So, combined endpoint (death + recurrent cardiovascular disease + repeated hospitalization) was achieved in 66 cases $(68.04 \%)$ in the group 1 and in $47(54.7 \%)$ in the group 2 ( $p=0.043$ ) (Fig. 1).

Patients of the examined groups had similar lipid pro-
Examination (MMSE) и National Institutes of Health Stroke Scale (NIHSS), Скандинавской шкале.

Также всем пациентам в 1, 7, 21, 90, 180 и 360 дни проводился подсчет клеток десквамированного эндотелия в плазме.

Данные были классифицированы по типу наблюдаемых признаков, проверены на предмет характера распределения (с помощью критерия Шапиро-Уилка) и соответствующим образом описаны. Точность количественных данных определялась точностью измерений того метода или прибора, с которого сняты показания. Затем было произведено сравнение исследуемых групп. Статистическая обработка проводилась с использованием стандартных методов вариационной статистики. Распределение вариант изучаемых параметров было нормальным или близким к нормальному, что позволило применить параметрические критерии для статистического анализа. Для сравнения величин применяли $\mathrm{t}$ тест Стьюдента. Достоверными считались различия, если полученное значение р для данного критерия (теста) ниже критического уровня значимости $\alpha=0,05$. 
Table 4. The rate of lethal events during the follow-up

Таблица 4. Частота летальных событий за время исследования

\begin{tabular}{|c|c|c|c|}
\hline Event / Событие & $\begin{array}{c}\text { Group } 1 / \\
\text { Группа } 1 \\
(n=97) \\
\end{array}$ & $\begin{array}{c}\text { Group } 2 / \\
\text { Группа } 2 \\
(n=86)\end{array}$ & $p$ \\
\hline $\begin{array}{l}\text { Death of ischemic stroke in hospital / } \\
\text { Смерть от ишемического инсульта } \\
\text { в стационаре, n (\%) }\end{array}$ & $3(3.1 \%)$ & $2(2.36 \%)$ & 0.88 \\
\hline $\begin{array}{l}\text { Death of recurrent ischemic stroke / } \\
\text { Смерть от повторного ишемического } \\
\text { инсульта, n (\%) }\end{array}$ & $7(7.2 \%)$ & $8(9.3 \%)$ & 0.83 \\
\hline $\begin{array}{l}\text { Death of MI / } \\
\text { Смерть от ИM, n (\%) }\end{array}$ & $6(6.2 \%)$ & $3(3.49 \%)$ & 0.64 \\
\hline $\begin{array}{l}\text { The total of deceased / } \\
\text { Bсего умерших, n (\%) }\end{array}$ & $16(16.5 \%)$ & $13(15.12 \%)$ & 0.98 \\
\hline
\end{tabular}

Table 5. The incidence of non-lethal cardiovascular events during the study

Таблица 5. Частота нежелательных сердечно-сосудистых событий за время исследования

\begin{tabular}{|c|c|c|c|}
\hline Disease / Заболевание & $\begin{array}{c}\text { Group } 1 / \\
\text { Группа } 1 \\
(n=97)\end{array}$ & $\begin{array}{c}\text { Group } 2 / \\
\text { Группа } 2 \\
(n=86)\end{array}$ & $p$ \\
\hline $\begin{array}{l}\text { Ischemic stroke / } \\
\text { Ишемический инсульт, n (\%) }\end{array}$ & $7(7.2 \%)$ & $4(4.65 \%)$ & 0.70 \\
\hline $\begin{array}{l}\text { Hemorrhagic stroke / } \\
\text { Геморрагический инсульт, n (\%) }\end{array}$ & 0 & $1(0.86 \%)$ & 0.95 \\
\hline $\mathrm{Ml} / \mathrm{hM}, \mathrm{n}(\%)$ & $5(5.15 \%)$ & $4(4.65 \%)$ & 0.84 \\
\hline PЕ / ТЭЛА, n (\%) & 0 & $1(0.86 \%)$ & 0.95 \\
\hline The total / Всего, n (\%) & $12(12.37 \%)$ & $10(11.63 \%)$ & 0.92 \\
\hline \multicolumn{4}{|c|}{$\begin{array}{l}\text { MI - myocardial infarction, PE - pulmonary embolism } \\
\text { ИМ - инфаркт миокарда, ТЭЛА - тромбоэмболия легочной артерии }\end{array}$} \\
\hline
\end{tabular}

file at admission and did not differ in the TC, LDL cholesterol and TG levels. At that, first two indices were moderately increased in the both groups, while TG level did not exceed normal values (Table 1). All lipid profile indices of first group patients remained constant (unchanged) through the study. In turn, simvastatin treated patients of the second group revealed significant decrease in TC and LDL cholesterol levels by the 90th day of the follow-up and their target levels (for high-risk patients) by the 180th day, which were kept until the end of the study (Table 6).

It should be noted that while TG level was normal in patients of the both groups, it decreased significantly in patients of the second group during the follow-up, and at that remained the same in the first group patients. These data confirm well-known simvastatin influence on the both atherogenic fractions of serum lipids.

Table 7 presents neurological status dynamics estimated by Scandinavian, MMSE and NIHHS scales. In accordance to each of the scales initial neurological status did not significantly differ between the groups.
Статистическую обработку исследования произвели при помощи статистического пакета STATISTICA ${ }^{\circledR}$ (Data analysis software system, StatSoft Inc, 2004) версия 7.0.

\section{Результаты}

В результате рандомизации пациенты не различались по основным клинико-демографическим показателям (табл. 1). Также не отмечалось различий по сопутствующим заболеваниям (табл. 2) и характеру проводимой терапии (табл. 3).

Из включенных в исследование 183 пациентов к 90-му дню наблюдения умерли 9 больных, в том числе 6 в первой и 3 во второй группе, а к середине наблюдения (180 суток) 11 и 8 человек, соответственно ( $>0,05)$. В конце периода наблюдения число умерших пациентов в первой группе по-прежнему было выше, но эти различия не имели статистической значимости ( 16 умерших в группе 1 и 13 - в группе 2; см. табл. 4).

Сердечно-сосудистые события за период исследования наблюдались в обеих группах примерно с равной частотой: 12,37\% (n=12) в первой группе и 11,63\% $(n=10)$ во второй группе ( $\mathrm{p}>0,05)$ (табл. 5).

Кроме того, в 1-й группе были госпитализированы по различным причинам 38 (39,2\%) пациентов, во 2-й группе 24 (27,9\%) пациента. Таким образом, комбинированная конечная точка (смерть + повторные сердечно-сосудистые заболевания + повторные госпитализации) была достигнута в 66 (68,04\%) случаях в первой группе, и в 47 (54,7\%) во второй ( $p=0,043)$ (рис. 1).

При поступлении изучаемые группы больных имели сходный липидный профиль и не различались по содержанию OX, X-ЛПНП и ТГ в крови. Следует отметить, что если два первых показателя были умеренно повышены в каждой из групп, то содержание ТГ не превышало нормальных значений (табл. 1). Все показатели липидного спектра не менялись в группе 1 на протяжении исследования. В свою очередь в группе 2 в ходе терапии симвастатином значимое снижение уровней ОХ и Х-ЛПНП отмечалось уже на 90-е сут наблюдения и достигало нормальных для больных высокого риска значений к 180-му дню, сохраняясь таким до конца исследования (табл. 6).

Следует отметить, что хотя уровень триглицеридов у пациентов обеих групп в течение всего времени наблюдения не превышал нормальных значений, этот показатель значимо регрессировал у пациентов группы 2, оставаясь неизменным у пациентов группы 1. Эти данные подтверждают хорошо известное влияние симвастатина на обе атерогенные фракции липидного спектра. 
Table 6. Dynamics of lipid profile indices

Таблица 6. Динамика показателей липидного спектра

\begin{tabular}{|c|c|c|c|c|c|c|c|c|}
\hline \multirow[t]{2}{*}{ Index / Параметр } & \multicolumn{4}{|c|}{ Group 1 / Группа 1} & \multicolumn{4}{|c|}{ Group 2 / Группа 2} \\
\hline & $\begin{array}{c}\text { Initially/ } \\
\text { Исходно } \\
(n=97)\end{array}$ & $\begin{array}{c}90 \text { days later/ } \\
\text { Через } 90 \text { дней } \\
(n=91)\end{array}$ & $\begin{array}{c}180 \text { days later/ } \\
\text { Через } 180 \text { дней } \\
(n=86)\end{array}$ & $\begin{array}{c}360 \text { days later/ } \\
\text { Через } 360 \text { дней } \\
(n=81)\end{array}$ & $\begin{array}{c}\text { Initially/ } \\
\text { Исходно } \\
(n=86)\end{array}$ & $\begin{array}{c}90 \text { days later/ } \\
\text { Через } 90 \text { дней } \\
(n=83)\end{array}$ & $\begin{array}{c}180 \text { days later/ } \\
\text { Через } 180 \text { дней } \\
(n=78)\end{array}$ & $\begin{array}{c}360 \text { days later/ } \\
\text { Через } 360 \text { дней } \\
(n=73)\end{array}$ \\
\hline TC, mmol/l / OX, ммоль/л & $5.22 \pm 1.7$ & $4.97 \pm 1.1$ & $5.15 \pm 0.7$ & $5.23 \pm 1.0$ & $5.47 \pm 1.3$ & $5.13 \pm 1.06 * * *$ & $4.85 \pm 0.69 * * *+\dagger$ & $4.72 \pm 0.6^{* * *++\dagger}$ \\
\hline TG, mmol/l / ТГ, ммоль/л & $1.03 \pm 0.2$ & $0.92 \pm 0.2$ & $0.96 \pm 0.3$ & $1.05 \pm 0.37$ & $1.16 \pm 0.4$ & $1.07 \pm 0.3^{*+t+}$ & $1.01 \pm 0.22^{* * * *+}$ & $0.96 \pm 0.2^{* *+\dagger}$ \\
\hline $\begin{array}{l}\text { LDL cholesterol, mmol/l / } \\
\text { Х-ЛПНП, ммоль/л }\end{array}$ & $2.23 \pm 0.9$ & $2.14 \pm 0.5$ & $2.3 \pm 0.4$ & $1.8 \pm 0.3$ & $2.2 \pm 0.6$ & $2.0 \pm 04^{* * *}$ & $1.87 \pm 0.33^{* * *++t}$ & $1.8 \pm 0.3^{* * *+t \dagger}$ \\
\hline \multicolumn{9}{|c|}{$\begin{array}{l}\text { TC - total cholesterol, LDL - low density lipoproteins, TG - triglycerides } \\
\text { OХ - общий холестерин, X-ЛПНП - холестерин липопротеинов низкой плотности, ТГ - триглицериды } \\
{ }^{*} \text { р }<0.05,{ }^{* *} p<0.01,{ }^{* * *} p<0.001 \text { (as compared to initial values); }+ \text { p }<0.05,++p<0.01,++t p<0.001 \text { (as compared to similar indices of the other group) } \\
{ }^{*} p<0,05,{ }^{* *} p<0,01,{ }^{* * *} p<0,001 \text { (по сравнению с исходными значениями); }+p<0,05,++p<0,01,++t p<0,001 \text { (по сравнению с аналогичными показателями противоположной группы) }\end{array}$} \\
\hline
\end{tabular}

Table 7. Neurological status dynamics by NIHHS (points) Таблица 7. Динамика неврологического статуса по шкале NIHHS (баллы)

\begin{tabular}{|c|c|c|}
\hline $\begin{array}{l}\text { Day of the study / } \\
\text { День исследования }\end{array}$ & $\begin{array}{l}\text { Group 1/ } \\
\text { Группа } 1\end{array}$ & $\begin{array}{l}\text { Group } 2 \text { / } \\
\text { Группа } 2\end{array}$ \\
\hline 1 & $9.19 \pm 3.74$ & $8.86 \pm 4.02$ \\
\hline 7 & $8.57 \pm 3.95^{* * *}$ & $8.1 \pm 3.8^{* * *}$ \\
\hline 21 & $6.9 \pm 3.79 * * *$ & $6.63 \pm 3.5^{* * *}$ \\
\hline 90 & $5.57 \pm 3.15^{* * *}$ & $5.08 \pm 2.7^{* * *}$ \\
\hline 180 & $5.05 \pm 3.11^{* * *}$ & $4.39 \pm 2.1^{* * *++\dagger}$ \\
\hline 360 & $4.8 \pm 3.07^{* * *}$ & $3.77 \pm 1.8^{* * *++\dagger}$ \\
\hline \multicolumn{3}{|c|}{$\begin{array}{l}{ }^{*} p<0.05,{ }^{* *} p<0.01,{ }^{* * *} p<0.001 \text { (as compared to initial values); }+p<0.05 \text {, } \\
+t p<0.01,++t p<0.001 \text { (as compared to similar indices of the other group) } \\
{ }^{*} p<0,05,{ }^{* *} p<0,01,{ }^{* * *} p<0,001 \text { (по сравнению с исходными } \\
\text { значениями); }+p<0,05,+t p<0,01,++t p<0,001 \text { (по сравнению } \\
\text { с аналогичными показателями противоположной группы) }\end{array}$} \\
\hline
\end{tabular}

NIHHS estimates consciousness level, elementary cognitive functions (memory, attention) and basic neurological abnormalities (paresis, visual impairments and sensibility). The less points a stroke patient has by NIHHS, the better his neurological status; as against two

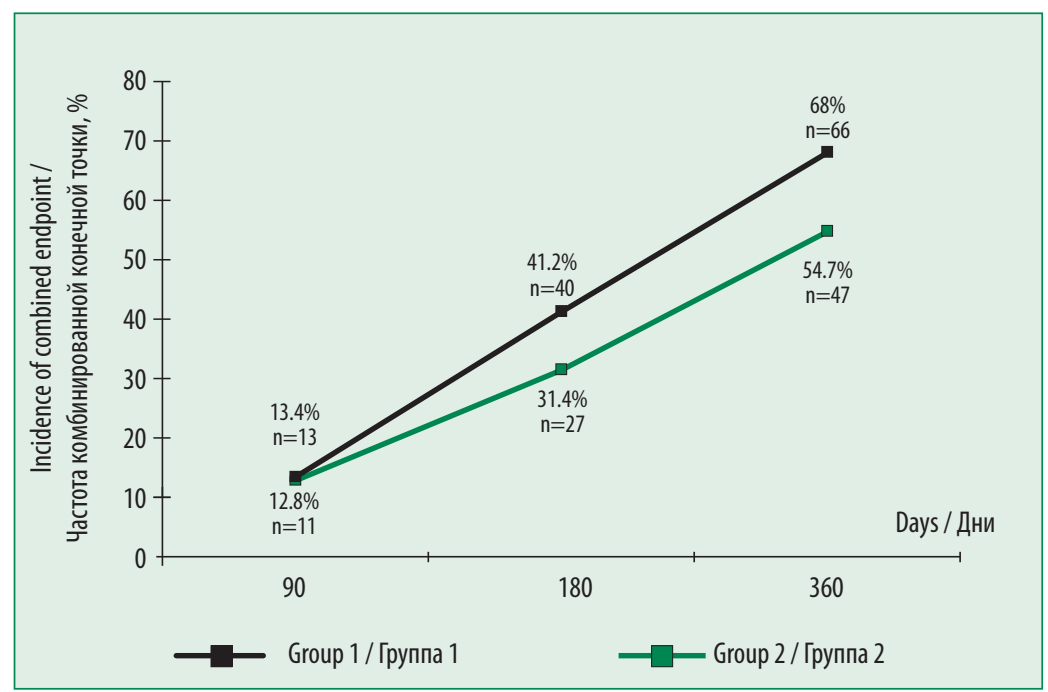

Figure 1. The incidence of the combined endpoint

Рисунок 1. Частота комбинированной конечной точки
Динамика неврологического статуса больных, оцененная с помощью шкал скандинавской, MMSE и NIHHS, представлена в табл. 7. По каждой из них исходный неврологический статус пациентов не имел достоверных различий между группами

Шкала NIHHS оценивает уровень сознания и элементарные когнитивные функции (память, внимание), а также основные неврологические нарушения (парезы, нарушения зрения, чувствительность). В отличие от двух других шкал, в которых положительную динамику в состоянии больных с нарушением мозгового кровообращения отражает максимальное число баллов, позитивная оценка по NIHHS подразумевает их минимизацию.

В нашем исследовании улучшение показателей по шкале NIHHS было зафиксировано также в каждой из групп, но у пациентов группы 2 это улучшение было более отчетливым. При этом межгрупповое различие показателей (табл. 7) было высокозначимым ( $p<0,001)$.

Шкала MMSE (Folstein M. et al., адаптированная в 1985 г) в баллах оценивает основные показатели когнитивных функций (ориентация, восприятие, внимание и счет, память, речь, чтение и письмо), затем подсчитывается суммарный балл (может составлять от 0 до 30). Более высокий суммарный балл свидетельствует о более высокой сохранности когнитивных функций. При оценке ментальных функций включенных в исследование пациентов также отмечалось более раннее восстановление когнитивных способностей у больных, принимающих 40 мг симвастатина (табл. 8).

При оценке неврологического статуса по Скандинавской шкале (Scandinavian Stroke Study Group, 1985 г) учитываются уровень сознания, ориентированность, речь, движение глаз, паралич лицевого нерва, походка; сила в баллах в руке, кисти, ноге, стопе. Оценка этих показателей в исследуемых группах продемонстрировала позитивное влияние как стандартного, так и дополненного назначением статина лечения. В каждой из групп отмечалось 
Simvastatin in acute period of ischemic stroke/Симвастатин в остром периоде ишемического инсульта

Table 8. Neurological status by MMSE scale (points) Таблица 8. Оценка неврологического статуса по шкале MMSE (баллы)

\begin{tabular}{|c|c|c|}
\hline $\begin{array}{l}\text { Day of the study / } \\
\text { День исследования }\end{array}$ & $\begin{array}{l}\text { Group 1/ } \\
\text { Группа } 1\end{array}$ & $\begin{array}{l}\text { Group } 2 \text { / } \\
\text { Группа } 2\end{array}$ \\
\hline 1 & $17.24 \pm 3.35$ & $17.41 \pm 3.8$ \\
\hline 7 & $18.02 \pm 3.36^{*}$ & $19.12 \pm 3.6^{* *+\dagger}$ \\
\hline 21 & $20.86 \pm 3.5^{* * *}$ & $21.6 \pm 3.1 * * *+\dagger$ \\
\hline 90 & $22.9 \pm 3.38^{* * *}$ & $24.0 \pm 2.8^{* * *++\dagger}$ \\
\hline 180 & $23.91 \pm 3.26^{* * *}$ & $24.89 \pm 2.02^{* * *+\dagger \dagger}$ \\
\hline 360 & $24.62 \pm 2.58^{* * *}$ & $26.21 \pm 1.58^{* * *+\dagger \dagger}$ \\
\hline \multicolumn{3}{|c|}{$\begin{array}{l}{ }^{*} p<0.05,{ }^{* *} p<0.01,{ }^{* * *} p<0.001 \text { (as compared to initial values); } t p<0,05, \\
+t p<0,01,+t+p<0,001 \text { (as compared to similar indices of the other group) } \\
{ }^{*} p<0,05,{ }^{* *} p<0,01,{ }^{* * *} p<0,001 \text { (по сравнению с исходными значе- } \\
\text { ниями); }+p<0,05,+t p<0,01,++t p<0,001 \text { (по сравнению с аналогичными } \\
\text { показателями противоположной группы) }\end{array}$} \\
\hline
\end{tabular}

Table 9. Neurological status by Scandinavian scale (points)

Таблица 9. Оценка неврологического статуса по Скандинавской шкале (баллы)

\begin{tabular}{|c|c|c|}
\hline $\begin{array}{l}\text { Day of the study / } \\
\text { День исследования }\end{array}$ & $\begin{array}{l}\text { Group 1/ } \\
\text { Группа } 1\end{array}$ & $\begin{array}{l}\text { Group } 2 \text { / } \\
\text { Группа } 2\end{array}$ \\
\hline 1 & $9.19 \pm 3.74$ & $8.86 \pm 4.02$ \\
\hline 7 & $8.57 \pm 3.95^{* * *}$ & $8.1 \pm 3.8^{* * *}$ \\
\hline 21 & $6.9 \pm 3.79 * * *$ & $6.63 \pm 3.5^{* * *}$ \\
\hline 90 & $5.57 \pm 3.15^{* * *}$ & $5.08 \pm 2.7^{* * *}$ \\
\hline 180 & $5.05 \pm 3.11^{* * *}$ & $4.39 \pm 2.1 * * *++\dagger$ \\
\hline 360 & $4.8 \pm 3.07^{* * *}$ & $3.77 \pm 1.8 * * *++\dagger$ \\
\hline \multicolumn{3}{|c|}{$\begin{array}{l}{ }^{*} p<0.05,{ }^{* *} p<0.01,{ }^{* * *} p<0.001 \text { (as compared to initial values); }+p<0.05 \text {, } \\
+t p<0.01,+t+p<0.001 \text { (as compared to similar indices of the other group) } \\
{ }^{*} p<0,05,{ }^{* *} p<0,01,{ }^{* * *} p<0,001 \text { (по сравнению с исходными } \\
\text { значениями); }+p<0,05,+t p<0,01,+++p<0,001 \text { (по сравнению с аналогич } \\
\text { ными показателями противоположной группы) }\end{array}$} \\
\hline
\end{tabular}

Table 10. Dynamics of desquamated endotheliocytes number in DM type 2 patients

Таблица 10. Динамика количества слущенных клеток эндотелия у пациентов с СД ІІ типа

\begin{tabular}{lcc}
\hline $\begin{array}{l}\text { Day of the study / } \\
\text { День исследования }\end{array}$ & $\begin{array}{c}\text { Group 1/ } \\
\text { Группа 1 }\end{array}$ & $\begin{array}{c}\text { Group 2 / } \\
\text { Группа 2 }\end{array}$ \\
\hline 1 & $20.1 \pm 5.2$ & $20.38 \pm 2.5$ \\
\hline 7 & $15.8 \pm 3.2^{* *}$ & $15.38 \pm 3.3^{* *}$ \\
\hline 21 & $13.3 \pm 3.3^{* *}$ & $14.13 \pm 3.8^{* *}$ \\
\hline 90 & $17.22 \pm 2.3^{*}$ & $12.13 \pm 3.4^{* *+\dagger}$ \\
\hline 180 & $18.0 \pm 1.6^{* *}$ & $10.28 \pm 2.5^{* *++十}$ \\
\hline 360 & $15.89 \pm 3.5^{*}$ & $9.57 \pm 1.5^{* *++\dagger}$ \\
\hline
\end{tabular}

${ }^{*} p<0.05,{ }^{* *} p<0.01,{ }^{* * *} p<0.001$ (as compared to initial values); $+p<0.05$ $+t p<0.01, t+t p<0.001$ (as compared to similar indices of the other group) ${ }^{*} p<0,05,{ }^{* *} p<0,01,{ }^{* * *} p<0,001$ (по сравнению с исходными значениями); $t p<0,05,+t p<0,01,++t p<0,001$ (по сравнению с аналогичными показателями противоположной группы)
Table 11. Studied indices at postponed and short-term statins intake

Таблица 11. Изучаемые показатели при отсроченном непродолжительном приеме статинов

\begin{tabular}{|c|c|c|c|}
\hline $\begin{array}{l}\text { Index / } \\
\text { Показатель }\end{array}$ & $\begin{array}{c}\text { Group } 1 . \\
\text { With statins } \\
\text { intake/ } \\
\text { Группа } 1 \\
\text { С приемом } \\
\text { статинов } \\
\text { (n=17) }\end{array}$ & $\begin{array}{c}\text { Group } 1 . \\
\text { Without statins } \\
\text { intake / } \\
\text { Группа } 1 \\
\text { Без приема } \\
\text { статинов } \\
\text { (n=64) }\end{array}$ & $p$ \\
\hline TC, mmol/l / OХ, ммоль/л & $4.23 \pm 1.52$ & $5.53 \pm 1.41$ & 0.087 \\
\hline $\begin{array}{l}\text { LDL cholesterol, mmol/l / } \\
\text { Х-ЛПНП, ммоль/л }\end{array}$ & $2.07 \pm 0.32$ & $2.43 \pm 0.36$ & 0.12 \\
\hline TG, mmol/l / TГ, ммоль/л & $1.01 \pm 0.27$ & $1.12 \pm 0.42$ & 0.062 \\
\hline NIHSS, points / баллы & $4.62 \pm 2.97$ & $4.93 \pm 1.92$ & 0.14 \\
\hline MMSE, points / баллы & $24.83 \pm 1.58$ & $24.22 \pm 2.87$ & 0.55 \\
\hline $\begin{array}{l}\text { Scandinavian scale, points / } \\
\text { Скандинавская шкала, баллы }\end{array}$ & $4.68 \pm 3.27$ & $4.93 \pm 1.65$ & 0.62 \\
\hline $\begin{array}{l}\text { Count of desquamated } \\
\text { endotheliocytes / } \\
\text { Количество эндотелиоцитов, n } \\
\end{array}$ & $15.22 \pm 3.79$ & $16.28 \pm 3.55$ & 0.095 \\
\hline \multicolumn{4}{|c|}{$\begin{array}{l}\text { TC - total cholesterol, LDL - low density lipoproteins, TG - triglycerides } \\
\text { OХ - общий холестерин, Х-ЛПНП - холестерин липопротеинов низкой плотности, } \\
\text { ТГ - триглицериды } \\
\text { MMSE - Mini-Mental State Examination, NIHSS - National Institutes of Health Stroke Scale }\end{array}$} \\
\hline
\end{tabular}

значимое нарастание баллов к 90-му и далее к 180-му и 360-му дню наблюдения. Однако это нарастание было более быстрым и выраженным у пациентов группы 2. Абсолютные показатели оценки в этой группе были значимо выше, чем в группе 1, как при промежуточной оценке, так и в конце исследования (табл. 9).

Число клеток десквамированного эндотелия подсчитывалось в динамике с использованием методики Hladovec J. [30]. Из рис. 2 следует, что на фоне стандартного лечения в группе 1 , хотя и наблюдалось значимое уменьшение количества эндотелиоцитов через 1 и 3 нед лечения, в дальнейшем число их даже возросло, хотя и оставалось значимо ниже по отношению к исходному уровню. Напротив, в группе 2 значимая разница по сравнению с исходным значением постоянно увеличивалась на протяжении исследования, достигнув в конце периода на-

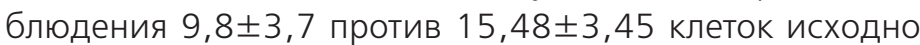
$(p<0,001)$.

Динамика количества эндотелиоцитов в поле зрения представлена на рис. 2, который демонстрирует финальное снижение этого показателя на 44,3\% в группе больных, лечившихся симвастатином, и только на 13,8\% у пациентов на фоне стандартной терапии.

Наиболее выраженное снижение числа клеток десквамированного эндотелия отмечено у пациентов 2 группы имеющих сахарный диабет 2-го типа (табл. 10).

За время нашего исследования 17 пациентов из группы 1 начали принимать различные статины в связи с перене- 
other scales, which reflect positive dynamics when the score is maximal.

The patients of the both groups demonstrated improvement by NIHHS, but the second group patients progressed more distinctly. At that, indices differed significantly between the groups $(p<0.001)$ (Table 7).

MMSE scale (adapted by Folstein M. et al, 1985) appraises by points basic cognitive functions (orientation, perception, attention and calculating, memory, speech, reading and writing), then summary score is calculated which varies from 0 to 30 points. The higher summary score indicates more preserved cognitive functions. Simvastatin treated patients revealed earlier recovering of mental functions (Table 8).

Scandinavian scale (Scandinavian Stroke Study Group, 1985) to assess neurological status takes into account the following: consciousness level, orientation, speech, eyes movement, facial palsy, gait, arm, hand, leg and foot motor power expressed in points. Both standard and supplemented by statin therapies improved these indices in the both examined groups. Patients of each group demonstrated significant increase in a number of points to $90^{\text {th }}$ and then - to $180^{\text {th }}$ and $360^{\text {th }}$ days of the follow-up. However this increase was faster and more significant in the second group. Absolute values of score in this group were significantly higher than these in the first one during the interim evaluation and in the end of the study (Table 9).

Desquamated endotheliocytes were counted by the J. Hladovec's method [30]. Fig. 2 demonstrates significant decrease in the count of desquamated endotheliocytes in the first group after 1 and 3 weeks of the standard treatment, however in the following their content increased being at that significantly lower as compared to the initial level. On the contrary, the second group revealed significant distinction in the count of desquamated endotheliocytes as compared to the initial level with permanent increasing of this distinction through the study, which achieved $9.8 \pm 3.7$ by the end of the follow-up vs $15.48 \pm 345$ cells initially $(p<0.001)$.

Figure 2 presents final decrease in endotheliocytes number by $44.3 \%$ in the simvastatin treated patients and by $13.8 \%$ only in those who received standard therapy.

Most significant decrease in desquamated endotheliocytes amount was noted in the second group patients with diabetes mellitus of type 2 (Table 10).

During our study 17 patients of the first group started to intake different statins because of repeated cardiovascular events, second stroke or comorbidity. Statins were represented by сенными повторными сердечно-сосудистыми событиями, перенесенным инсультом или сопутствующей патологией. Из статинов присутствовали дженерики симвастатина ( $n=12)$ в суточной дозе 10-20 мг/сут или аторвастатин ( $n=7)$ в аналогичной дозе. В среднем прием статинов был начат через 205,3 334,6 дней от перенесенного инсульта. В связи с тем, что большинство пациентов начали принимать статины более чем через полгода от момента инсульта, было проведено сравнение ряда показателей (уровень ОX, Х-ЛПНП, ТГ, неврологический статус, циркулирующие эндотелиоциты) между пациентами 1 группы, принимавшими и не принимавшими статины к 360-м суткам наблюдения (табл. 11).

Как видно из приведенных данных, непродолжительный и отсроченный прием статинов в низких дозах не оказал существенного влияния на исследуемые параметры.

\section{Обсуждение}

В последние годы все более активно используются статины как в первичной, так и во вторичной профилактике ишемического инсульта различной этиологии. В России статины принимают лишь 5\% больных ишемической болезнью сердца (ИБС), и то непостоянно. Возможно, именно поэтому смертность от сердечно-сосудистых заболеваний за последние 10 лет в нашей стране постоянно превышает 1 млн чел, а это более половины всех случаев смертности [32].

По данным Шальновой С.А. и соавт. [33], статины в РФ в течение 3 лет принимают менее 6\% больных (из числа тех,

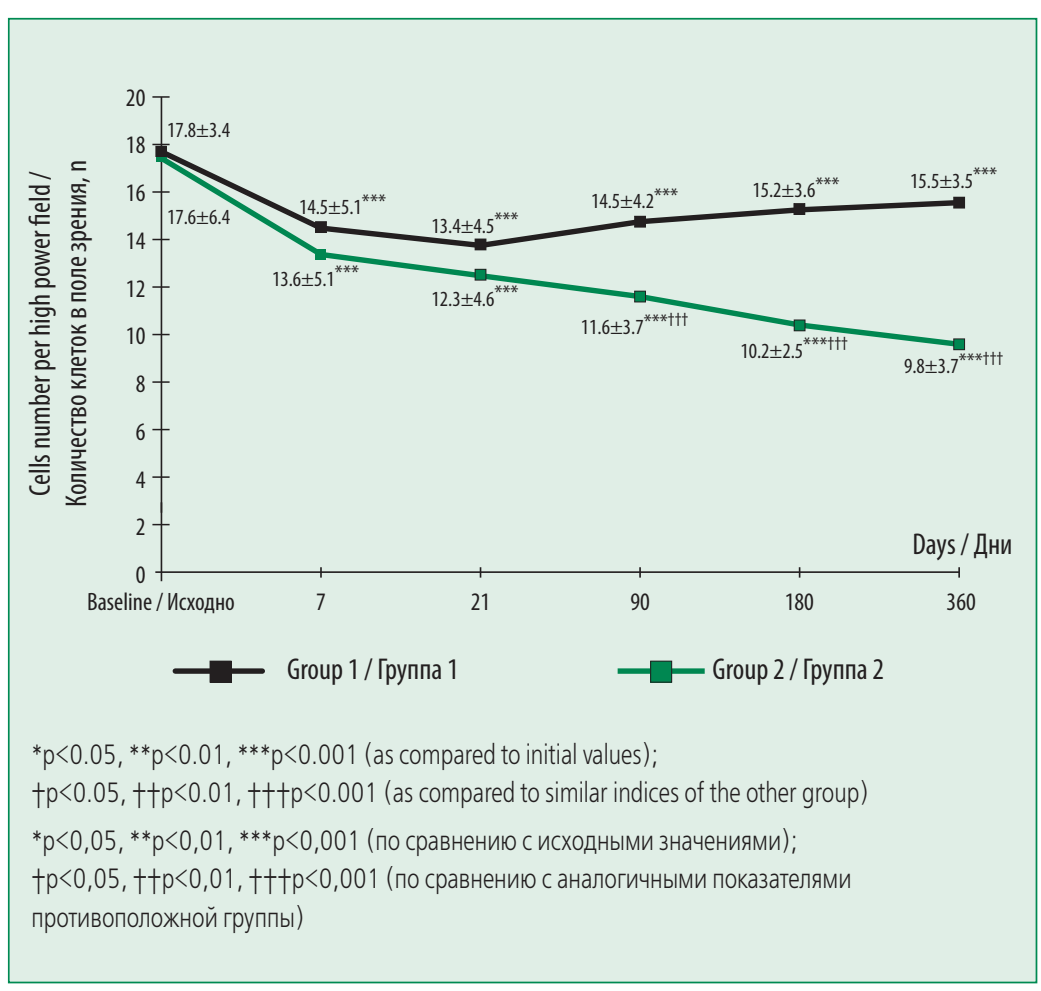

Figure 2. Dynamics of desquamated endotheliocytes count through the follow-up

Рисунок 2. Динамика числа клеток десквамированного эндотелия за время наблюдения 
simvastatin generics $(n=12)$ in the daily dose of 10 $20 \mathrm{mg}$ or by atorvastatin $(n=7)$ in the same doses. At average these patients started to take statins $205.3 \pm 34.6$ days after the stroke. Because of the fact that majority of the patients started statin therapy more than half-year after the stroke, we compared a number of indices (TC, LDL cholesterol, TG, neurological status, desquamated endotheliocytes) between patients of the first group who were or weren't receiving statins by the $360^{\text {th }}$ day of the follow-up (Table 11).

As it can be seen postponed and short-term intake of statins in low doses did not significantly impact on examined parameters.

\section{Discussion}

In recent years, statins have been more and more actively used in primary and secondary prevention of IS. Only $5 \%$ of ischemic heart disease (IHD) patients in Russia receive statins, besides irregularly. This is a possible reason for high cardiovascular mortality rate in our country in the last ten years which exceeds 1 million people per year, and that is more than a half of all cases of death [32].

In accordance to Shalnova S.A. et al. data [33] less than $6 \%$ of those who were prescribed statins really intake them. Consequently, it is supposed that the stroke patients are prescribed these drugs even more seldom and take them irregularly as well. However inhibitors of HMG-COA-reductase decrease IS risk in IHD patients more significantly than in patients without IHD [34].

While role of high TC level as a risk factor for IHD is doubtless, association of TC with stroke risk is questionable and depends on its type. For example, no distinct correlation between TC level and stroke incidence was revealed by meta-analysis of 45 prospective studies with a total number of strokes 13000 in 450000 enrolled patients [35]. But pattern is changed if stroke type is taken into account (ischemic or hemorrhagic). Some researchers demonstrated increase in hemorrhagic strokes incidence in statins usage [36, 37]. At that, meta-analysis of 26 studies including 100560 statin treated patients revealed significant decrease in IS incidence [odds ratio (OR) 0.79; $95 \%$ confidence interval $(\mathrm{Cl})$ 0.63-0.99] at slight increase in hemorrhagic stroke risk (OR $1.11 ; 95 \% \mathrm{Cl}$ 0.77-1.60) [38]. In accordance to some data [39] preceding statins intake decreases hemorrhagic stroke risk during thrombolytic therapy [39].

In majority of authors' opinion stroke prevention due to statins administration is primarily associated with slowdown of cerebral atherosclerosis and mainly correlates with LDL cholesterol level decrease [39-42]. Statins anti-inflammatory effect has also some importance since inflammation is a significant factor of кому статины назначались). Соответственно, можно считать, что данные препараты после перенесенного ишемического инсульта назначаются еще реже, а пациенты принимают их так же нерегулярно. Тем не менее, ингибиторы ГМК-редуктазы уменьшают риск развития ишемического инсульта в большей степени у пациентов с ИБС, чем при ее отсутствии [34].

Если роль повышения ОХ как фактора риска ИБС не вызывает сомнений, то ассоциация ОХ с риском мозгового инсульта неоднозначна и зависит от характера последнего. Например, мета-анализ 45 проспективных исследований с общим количеством инсультов 13000 у 450000 включенных больных не выявил четкой взаимосвязи между уровнем ОХ крови и частотой возникновения мозговых инсультов [35]. Но, когда учитывается характер инсульта (ишемический или геморрагический), картина меняется. Существует мнение, что применение данной группы препаратов ведет к увеличению числа геморрагических инсультов [36,37]. В то же время, проведенный в 2007 г. метаанализ 26 исследований, включавших 100560 пациентов, показал, что применение статинов ведет к значительному уменьшению числа ишемических инсультов [относительный риск (OP) 0,79; $95 \%$ доверительный интервал (ДИ) 0,63-0,99] при незначительном увеличении риска кровоизлияний в головной мозг (ОР 1, 11; 95\% ДИ 0,77-1,60) [38]. В настоящее время существуют данные, что предшествующее применение статинов уменьшает риск развития внутримозгового кровоизлияния при проведении тромболитической терапии [39].

По мнению большинства авторов, ведущее значение в предупреждении развития инсульта при лечении статинами связано с замедлением прогрессирования атеросклероза церебральных сосудов и коррелирует, прежде всего, со снижением уровня Х-ЛПнП [39-42]. Определенную роль может играть и противовоспалительный эффект статинов, поскольку в патогенезе развития и прогрессирования атеросклероза важная роль отводится процессам воспаления $[34,41]$.

В предупреждении частоты развития инсульта при лечении статинами может играть роль и положительное влияние препаратов данной группы на эндотелий сосудов, реологические свойства крови, агрегацию тромбоцитов [43].

Большое значение имеет использование статинов в комбинированной терапии с целью профилактики инсульта. Пациенты с ишемическим инсультом, получавшие до его развития статины [44] в сочетании с антитромбоцитарными средствами [45] и ингибиторы АПФ, имели меньшую степень неврологического дефицита и меньший объем поражения головного мозга, по данным магнитно-резонансной томографии $[46,47]$.

Ранняя и быстрая диагностика эндотелиальной дисфункции, которой отводится большая роль в развитии сердечно-сосудистых заболеваний в целом и инсультов в 
atherosclerosis onset and progression $[34,41]$.

Positive statins influence on vascular endothelium, blood rheology, platelet aggregation is also of concern for stroke prevention [43].

Administration of statins as a part of combined therapy aimed at stroke prevention is very important. Patients, who received statins [44] in combination with antiplatelet agents [45] and ACE inhibitors before stroke, revealed less neurological deficit and less extent of brain damage in accordance to magnetic resonance tomography data $[46,47]$.

Endothelial dysfunction plays an important role in cardiovascular diseases development including strokes, so, it should be diagnosed early and promptly. The count of desquamated endotheliocytes is one of such quick and reliable methods. The procedure is successfully used in majority of cardiovascular diseases: HT [48], acute and severe $\mathrm{CHF}[48,39]$, myocardial infarction and unstable $[49,50]$ and stable angina [33], pulmonary hypertension [45]. At that the disease severity directly correlates with the number of endotheliocytes.

At the present day there are many studies in which neurological status was estimated in statins administration. The common international scales are implemented for this aim: Rankin, MMSE, NIHSS [49].

The main purposes of statins administration in IS patient are the following:

- decrease in recurrent IS risk;

- decrease in transient ischemic attack risk;

- decrease in coronary complications risk at concomitant IHD, diabetes mellitus.

\section{Conclusion}

Our study testifies that simvastatin (Zocor forte) 40 $\mathrm{mg} /$ day being prescribed along with neuroprotective and antihypertensive treatment in acute stage of IS promotes lowering of recurrent cardiovascular events rate, distinct positive dynamics of neurological status, regression of endothelial dysfunction in terms of decrease in circulating desquamated endotheliocytes number. частности, может послужить важным подспорьем в дальнейшем лечении. Одним из таких быстрых и достоверных методов является определение десквамированных эндотелиоцитов в плазме. Данный метод зарекомендовал себя при большинстве сердечно-сосудистых заболеваний: гипертонической болезни [48], острой и тяжелой ХСН [48,39], ИМ и нестабильной стенокардии $[49,50]$, стабильной стенокардии [33], легочной гипертензии [45], причем тяжесть заболевания напрямую связана с количеством эндотелиоцитов.

В настоящее время все больше появляется исследований, связанных с изучением неврологического статуса при применении статинов. Для этого используются наиболее распространенные в международной практике шкалы: Rankin, MMSE, NIHSS [49].

Основными целями применения статинов у больного с ишемическим инсультом являются:

- снижение риска развития повторного ишемического инсульта;

- снижение риска развития преходящих нарушений мозгового кровообращения;

- снижение риска коронарных осложнений при сопутствующей ИБС, сахарном диабете.

\section{Заключение}

Полученные в исследовании результаты свидетельствуют о том, что назначение 40 мг симвастатина (Зокор форте) начиная с острой фазы ишемического инсульта наряду с сопутствующей нейропротекторной и антигипертензивной терапией способствует:

1. уменьшению количества повторных кардиоваскулярных катастроф;

2. отчетливой положительной динамике неврологического статуса;

3. регрессу проявлений эндотелиальной дисфункции в виде значительного уменьшения количества циркулирующих в крови клеток десквамированного эндотелия. 


\section{References / Литература}

1. Bonita R. Stroke prevention: a global perspective. In: Norris JW, Hachinsky V, eds. Stroke Prevention. New York, NY: Oxford University Press; 2001:259-74.

2. World Health Organization (WHO). The World Health Report. Geneva: WHO; 1999.

3. American Heart Association. 2001 Heart and stroke statistical update. Dallas, Texas: American Heart Association; 2001.

4. Bonita R. Epidemiology of stroke. Lancet 1992;339:342-4

5. Kalashnikova L.A., Konovalov R.N., Dobrynina L.A. Ischemic stroke in spontaneous dissection of the isolated posterior cerebral arteries at a young age. Zhurnal nevrologii i psikhiatrii imeni S.S. Korsakova 2009; 109 (5) suppl 2: 3-10. Russian (Калашникова Л.А., Коновалов Р.Н., Добрынина Л.А. Ишемический инсульт при спонтанной изолированной диссекции задней мозговой артерии в молодом возрасте. Журнал неврологии и психиатрии им. С.С. Корсакова 2009; 109 (5) приложение 2: 3-10).

6. Damulin I.V., Parfenov V.A., Skoromets A.A., Yakhno N.N. Circulatory disorders in the brain and spinal cord. In: Yakhno N.N., editor. Diseases of the nervous system. Guide for physicians. Vol 1. Moscow: Meditsina; 2005: 231-302. Russian (Дамулин И.В., Парфенов В.А., Скоромец А.А., Яхно Н.Н. Нарушения кровообращения в головном и спинном мозге. В: Яхно Н.Н., редактор. Болезни нервной системы. Руководство для врачей. Том 1. М.: Медицина; 2005: 231-302).

7. Suslina Z.A. Vascular disease of the brain in Russia: reality and prospects of solving the problem. Materials XIII International Conference on "Modern trends in neurology," April 27-29, 2001, Sudak (Ukraine); 2011. Russian (Суслина 3.А. Сосудистые заболевания головного мозга в России: реальность и перспективы решения проблемы. Материалы XIII Международной конференции «Актуальные направления в неврологии», $27-29$ апреля 2001 г., Судак (Украина). Судак; 2011).

8. Vibers D. Feigin, B., Brown R. Stroke: Clinical Manual. Moscow: Binom; 2005. Russian (Виберс Д., Фейгин В., Браун Р. Инсульт: Клиническое руководство. М.: Бином; 2005).

9. Sacco R.L., Adams R., Albers G. et al. Guidelines for Prevention of Stroke in Patients With Ischemic Stroke or Transient Ischemic Attack: A Statement for Healthcare Professionals From the American Heart Association/American Stroke Association Council on Stroke: Co-Sponsored by the Council on Cardiovascular Radiology and Intervention: The American Academy of Neurology affirms the value of this guideline. Stroke 2006; 37: $577-617$.

10. Bhatt D.L., Steg P.G., Ohman E.M. et al., for the REACH Registry Investigators. International prevalence, recognition, and treatment of cardiovascular risk factors in outpatients with atherothrombosis. JAMA 2006; 295:180-189

11. Suslina Z.A., Tanashyan M.M., Lagoda O.V. Atherosclerosis and ischemic cerebrovascular accidents. Aterotromboz 2009; (2): 60-67. Russian (Суслина 3.А., Танашян М.М., Лагода О.В. Атеросклероз и ишемические нарушения мозгового кровообращения. Атеротромбоз 2009; (2): 60-67).

12. Cooke J.P, Tsao P.S. Is NO an endogenous antiathero-genic molecule? Arterioscler Thromb 1994; 14 : 653-655.

13. Golovchenko, Y., Treschinskaya M.A. Pathogenetic features of the local regulation of cerebral blood flow in endothelial dysfunction. Materials XIII International Conference on "Modern trends in neurology," April 27-29, 2001, Sudak (Ukraine); 2011. (Головченко Ю.И., Трещинская М.А. Патогенетические особенности локальной регуляции мозгового кровообращения при эндотелиальной дисфункции. Материалы ХІІІ Международной конференции «Актуальные направления в неврологии», 27-29 апреля 2001 г., Судак (Украина). Судак; 2011).

14. Hirase T., Node K. Endothelial Dysfunction as a Cellular Mechanism for Vascular Failure. Am J Physiol Heart Circ Physiol 2011 [Epub ahead of print]

15. Sakurai K., Isahaya K., Takaishi S. et al. Effects of early statin treatment on inflammatory biomarkers and clinical deterioration in patients with acute ischemic stroke. Rinsho Shinkeigaku 2011;51(1):6-13.

16. Vane J.R., Anggard E.E., Batting R.M. Regulatory functions of the vascular endothelium. N Engl J Med 1990: 323: 27-36.

17. Vanhoutte P.M. How to assess endothelial function in human blood vessels. J Hypertens 1999; 17(8): 1047-1058.

18. Davies M.J., Thomas A.C. Plaque fissuring - the cause of acute myocardial infarction, sudden ischemic death, and creshendo angina. Brit Heart J 1985: 53 (4): 363-373.

19. Falk E., Shah P.K., Faster V. Coronary plaque disruption. Circulation 1995; 92: 657-671.

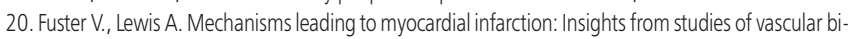
ology. Circulation 1994: 90: 2126-2146.

21. Calabrt P., Golia E., Yeh E.T. Role of C-Reactive Protein in Acute Myocardial Infarction and Stroke: Possible Therapeutic Approaches. Curr Pharm Biotechnol 2011 [Epub ahead of print]

22. Guidelines for the Prevention of Stroke in Patients With Stroke or Transient Ischemic Attack: A Guideline for Healthcare Professionals From the American Heart Association/American Stroke Association. Stroke 2011;42;227-276

23. Amarenco P., Bogousslavsky J., Callahan A. et al. High-dose atorvastatin after stroke or transient ischemic attack. N Engl J Med 2006; 335;549-559

24. Bianco M., Nombela F., Castellanos M. et al. Statin treatment withdrawal in ischemic stroke: A controlled randomized study. Neurology 2007; 69: 904-910.

25. Amarenco P., Labreuche J., Lavalle'e P., Touboul P-J. Statin in stroke prevention and carotid atherosclerosis: systematic review and meta-analysis. Stroke 2004; 35: 2902-9.

26. Plenge J.K., Hernandez T.L., Weil K.M. et al. Simvastatin Lowers C-Reactive Protein Within 14 Days An Effect Independent of Low-Density Lipoprotein Cholesterol Reduction. Circulation 2002;106:1447-52.
27. Fisher M. Injuries to the vascular endothelium: vascular wall and endothelial dysfunction. Rev Neurol Dis 2008; 5 Suppl 1:S4-11.

28. Dovgalevskiy P.Ya., Furman N.V. Stabilization of atherosclerotic plaques - the mainstay of treatment of acute coronary syndrome. Atmosfera. Kardiologiya 2004; (3): 6-10. Russsian (Довгалевский П.Я., Фурман Н.В. Стабилизация атеросклеротической бляшки - основа лечения острого коронарного синдрома. Атмосфера. Кардиология 2004; (3): 6-10).

29. Hladovec J. Circulating endothelial cells as a sign of vessel wall lesions. Physiol Bohemoslov 1978; 27 : 140-144.

30. Berkovich O.A., Belyaeva O.D., Bazhenova E.A. et al. Effect of statins on the functional state of the vascular endothelium in patients with coronary heart disease. Russkiy Meditsinskiy Zhurnal 2002; 10(19): 874-877. Russian (Беркович О.А., Беляева О.Д., Баженова Е.А. и др. Влияние статинов на функциональное состояние эндотелия сосудов у больных ишемической болезнью сердца. Русский Медицинский Журнал 2002; 10(19): 874-877.

31. Bory M., Sampol J., Yvorra S. et al. Detection des cellules endotheliales circulantes: un nouveau test diagniostique de l`angor de repos. Arch Mal Coeur Vaiss 1995;88(12):1827-1831.

32. Kukharchuk V.V. Lipid infiltration theory. Does changing the script? Kardiologicheskiy vestnik 2009 Volume I (XVI) (1): 63-66. Russian (Кухарчук В.В. Липидно-инфильтрационная теория. Действительно ли меняется сценарий? Кардиологический вестник 2009; том I (XVI) (1): 63-66).

33. Shal'nova S.A., Deev A.D., Oganov R.G. Factors influencing the mortality from cardiovascular disease Kardiovaskulyarnaya Terapiya i Profilaktika 2005; 4 (1): 4-9. Russian (Шальнова С.А., Деев А.Д., Оганов Р.Г. Факторы, влияющие на смертность от сердечно-сосудистых заболеваний. Кардиоваскулярная терапия и профилактика 2005; 4 (1): 4-9).

34. Nassief A., Marsh J.D. Statin therapy for stroke prevention. Stroke 2008;39(3):1042-8.

35. Prospective Studies Collaboration. Cholesterol, diastolic blood pressure, and stroke: 13,000 strokes in 450,000 people in 45 prospective cohorts. Lancet 1995;346:1647-53.

36. Blauw G.J., Lagaay A.M., Smelt A.H.M., Westendorp R.G.J. Stroke, statins, and cholesterol: a metaanalysis of randomized, placebocontrolled, doubleblind trials with HMG-CoA reductase inhibitors. Stroke 1997;28:946-50

37. Martinez-Ramirez S., Delgado-Mederos R., Marin R. et al. Statin pretreatment may increase the risk of symptomatic intracranial haemorrhage in thrombolysis for ischemic stroke: results from a case-control study and a meta-analysis. J Neurol 2011; 259(1): 111-8.

38. Henyan N.N., Riche D.M., East H.E., Gann P.N. Impact of Statins on Risk of Stroke: A Meta-Analysis. The Annals of Pharmacotherapy 2007:41(12):1937-1945.

39. Manktelow B.N., Potter J.F. Interventions in the Management of Serum Lipids for Preventing Stroke Recurrence Stroke 2009; 40: e622-e623.

40. Stoll G., Bendszus M. Inflammation and atherosclerosis: novel insights into plaque formation and destabilization. Stroke 2006; 37: 1923-32.

41. Switzer J.A., Hess D.C. Statin therapy for coronary heart disease and its effect on stroke. Curr Atheroscler Rep 2006; 8: 337-42.

42. Underhill H.R., Yuan C., Zhao X.Q. et al. Effect of rosuvastatin therapy on carotid plaque morphology and composition in moderately hypercholesterolemic patients: a high-resolution magnetic resonance imaging trial. Am. Heart J 2008; 155: e581-e588.

43. Fuentes B., Martínez-Sánchez P., Díez-Tejedor E. Lipid-lowering drugs in ischemic stroke prevention and their influence on acute stroke outcome. Cerebrovasc Dis 2009;27 Suppl 1:126-33.

44. Tsai N.W., Lin T.K., Chang W.N. et al. Statin pre-treatment is associated with lower platelet activity and favorable outcome in patients with acute non-cardio-embolic ischemic stroke. Crit Care 2011;15(4):R163.

45. Bull T.M., Golpon H. et al. Circulating endothelial cells in pulmonary hypertension. Thromb Haemost 2003;90(4):698-703.

46. Berkovich O.A., Ryabova T.S., Bazhenova E.A i dr. Effect of angiotensin-converting enzyme Kvadroprila on the functional state of vascular endothelium in patients with coronary heart disease with different genotypes of angiotensin-converting enzyme gene. Mezhdunarodnyy Meditsinskiy Zhurnal 2003; 6(2): 152-154. Russian (Беркович О.А., Рябова Т.С., Баженова Е.А и др. Влияние ингибитора ангиотензин-превращающего фермента Квадроприла на функциональное состояние эндотелия сосудов у больных ишемической болезнью сердца с различными генотипами гена ангиотензин-превращающего фермента. Международный Медицинский Журнал 2003; 6(2): 152-154).

47. Kumar S., Savitz S., Schlaug G. et al. Antiplatelets, ACE inhibitors, and statins combination reduces stroke severity and tissue at risk. Neurology 2006; 66: 1153-8. (13)

48. Almazov V.A., Sitnikov M.Yu., Ivanov S.G. et al. Carvedilol in the treatment of patients with chronic heart failure: clinical and metabolic effects. Serdechnaya Nedostatochnost' 2001; 2(2): 68-70. Russ$\operatorname{ian}$ (Алмазов В.А., Ситников М.Ю., Иванов С.Г. и др. Карведилол в лечении больных хронической сердечной недостаточностью: клинические и метаболические эффекты. Сердечная недостаточность 2001; 2(2): 68-70).

49. Boos C.J., Soor S.K., Kang D., Lip G.Y.N. Relationship between circulating endothelial cells and the predicted risk of cardiovascular events in acute coronary syndromes. Eur Heart J 2007; 28(9): 1092-1101.

50. Hladovec J., Prerovsky I., Stanek V., Fabian J. Circulating endothelial cells in acute myocardial infarction and angina pectoris. Klin Wochenschr 1978; 56: 1033-6.

Received/Поступила 29.11.2011 Accepted/Принята в печать 05.12.2011 